\title{
Avaliação da influência do Método Bailey no processo de dosagem e desempenho de misturas asfálticas
}

\author{
Larissa de Oliveira Mendes ${ }^{1}$ e Geraldo Luciano de Oliveira Marques ${ }^{2}$
}

\begin{abstract}
Resumo: Este trabalho tem por objetivo comparar, através de um programa experimental, misturas asfálticas dosadas por um Método Tradicional àquelas cujo proporcionamento dos agregados foi determinado pelo Método Bailey. O método Bailey diferencia-se dos métodos atualmente utilizados por, além de selecionar e avaliar a distribuição granulométrica dos agregados, se aproveitar da contribuição do esqueleto mineral sobre as características mecânicas das misturas asfálticas. O programa experimental comparou o desempenho de misturas cujo esqueleto mineral foi determinado através de duas maneiras diferentes (tradicional e Bailey), através de ensaios mecânicos e da consideração dos parâmetros obtidos na compactação giratória dos corpos de prova. Os resultados obtidos indicam a boa adequação do método Bailey na consideração do intertravamento das partículas para a obtenção de curvas granulométricas adequadas o que refletiu em melhoria de desempenho nas misturas estudadas. Será mostrado o desempenho quanto à rigidez, resistência, vida de fadiga e compactação giratória. DOI:10.4237/transportes.v20i4.574.
\end{abstract}

Palavras-chave: Método Bailey, misturas asfálticas, seleção granulométrica.

\begin{abstract}
This work aims to compare, through an experimental program, asphalt mixtures dosed by a traditional method to those whose household--the same proportion was given by Bailey. The Bailey method differs from the methods currently used for, in addition to selecting and evaluating the granulometric distribution of aggregates, to take advantage of the contribution of the mineral skeleton on the mechanical characteristics of asphalt mixtures. The experimental program compared the performance of mixes with mineral skeleton was determined by two different ways (traditional and Bailey), through mechanical tests and the consideration of the parameters obtained in gyratory compaction of specimens. The results obtained indicate good adaptation of the method in consideration of Bailey interlocking of particles for obtaining appropriate particle size curves which reflected in performance improvement in the mixtures studied. Performance will be shown on the stiffness, strength, fatigue life and gyratory compaction.
\end{abstract}

Keywords: Bailey Method, asphalt mixtures, granulometric selection.

\section{INTRODUÇÃO}

As misturas asfálticas utilizadas em revestimentos de pavimentos flexíveis têm o objetivo de proporcionar aos usuários segurança e conforto durante o tráfego, além de durabilidade e resistência às cargas que lhes são impostas.

Ao ser solicitado pelo tráfego ou por condições climáticas, o desempenho apresentado pelos revestimentos depende tanto das propriedades dos materiais constituintes quanto do proporcionamento desses materiais nas misturas (Nascimento, 2008).

Os agregados são, nas misturas, os principais responsáveis por resistirem à maior parte das cargas impostas ao pavimento, sendo fundamentais ao desempenho dos mesmos (Asphalt Institute, 1989). Dessa forma, as características dos agregados devem ser consideradas ainda no momento da dosagem, para que sejam obtidas misturas asfálticas mais resistentes.

Devido a essa resistência às cargas, os agregados podem ser considerados como o "esqueleto" da mistura, sendo que as propriedades que mais se relacionam a essa característica são a dureza, textura superficial, angularidade, forma e distribuição granulométrica.

Em contraponto aos tradicionais métodos de dosagem volumétricos (Marshall e SUPERPAVE, por exemplo), que consideram as características dos agregados utilizados de

\footnotetext{
${ }^{1}$ Larissa de Oliveira Mendes, Universidade Federal de Juiz de Fora, Juiz de Fora, MG, Brasil. (e-mail: larissa.mendes@engenharia.ufjf.br).

${ }^{2}$ Geraldo Luciano de Oliveira Marques, Universidade Federal de Juiz de Fora, Juiz de Fora, MG, Brasil. (e-mail: geraldo.marques@ufjf.edu.br).

Manuscrito recebido em 19/4/2012 e aprovado para publicação em 20/11/2012. Este artigo é parte de TRANSPORTES v. 20, n. 4, 2012. ISSN: 2237-1346 (online). DOI:10.4237/transportes.v20i4.574.
}

forma indireta e por tentativas, surgiu o Método Bailey para proporcionamento dos agregados nas misturas asfálticas propondo um intertravamento das partículas através de uma graduação contínua e balanceada. Esse método foi desenvolvido no departamento de transportes de Illinois (IDOT) e vem sendo utilizado e refinado desde a década de 1980 .

Esse trabalho teve por objetivo comparar misturas asfálticas dosadas utilizando-se o Método Tradicional de escolha do esqueleto mineral (método das tentativas) e misturas cujo esqueleto mineral foi determinado utilizando-se o Método Bailey. Para esta comparação, foram realizados ensaios de resistência à tração, Módulo de Resiliência e vida de fadiga, além da consideração dos parâmetros obtidos na compactação giratória dos corpos de prova.

\section{MÉTODO BAILEY}

O método Bailey foi criado na década de 1980, a fim de suprir a necessidade dos órgãos americanos no que diz respeito à capacidade de proporcionar um revestimento com resistência às deformações permanentes, às trincas por fadiga e ao desgaste, através da seleção sistemática da granulometria de misturas asfálticas.

Esse método tem por objetivo combinar os agregados, possibilitando, quando desejado, seu intertravamento e transformando-os no esqueleto da estrutura, além de utilizar uma graduação contínua e balanceada, completando a mistura (Vavrik et al., 2002).

O método apresenta uma diferente forma de classificação dos agregados graúdos e miúdos que se baseia no Tamanho Máximo Nominal (TMN) da mistura, denominando como agregados graúdos aqueles que formam vazios quando colocados em um volume definido e como agregados miúdos 
Tabela 1. Faixas recomendadas para as proporções de agregados em misturas (VAVRIK et al., 2002)

\begin{tabular}{lllllll}
\hline & \multicolumn{7}{l}{ Tamanho Máximo Nominal $(\boldsymbol{T M N}), \boldsymbol{e m} \mathbf{~ m m}$} \\
\cline { 2 - 7 } Proporção dos Agregados & 37,5 & 25,0 & 19,0 & 12,5 & 9,5 & 4,75 \\
\hline AG & $0,80-0,95$ & $0,70-0,85$ & $0,60-0,75$ & $0,50-0,65$ & $0,40-0,55$ & $0,30-0,45$ \\
GAF & $0,35-0,50$ & $0,35-0,50$ & $0,35-0,50$ & $0,35-0,50$ & $0,35-0,50$ & $0,35-0,50$ \\
FAF & $0,35-0,50$ & $0,35-0,50$ & $0,35-0,50$ & $0,35-0,50$ & $0,35-0,50$ & $0,35-0,50$ \\
\hline
\end{tabular}

aqueles capazes de preencher os vazios criados pelos agregados graúdos presentes na mistura.

Serão apresentados alguns conceitos básicos para o entendimento simplificado do método Bailey, maiores informações poderão ser obtidas em Vavrik et al (2001, 2002), Cunha (2004), Nascimento (2008) e Mendes (2011).

\subsection{Definição do Tamanho de Agregados para o Método Bailey}

Para poder diferenciar os agregados graúdos e miúdos, o método Bailey utiliza a Peneira de Controle Primário (PCP), que se baseia no TMN da mistura. A PCP é definida pela Equação 1.

$$
P C P=T M N \times 0,22
$$

em que,

$P C P$ : Peneira de Controle Primário; e

$T M N$ : Tamanho Máximo Nominal.

Através de análises em duas (2D) e três dimensões (3D) do arranjo de agregados de diferentes formas, chegou-se a fatores entre 0,18 e 0,28 que poderiam ser utilizados na Equação 1 , sem afetar a análise da granulometria. No entanto, padronizou-se o valor de 0,22 (Vavrik et al., 2001).

Os agregados graúdos são, então, aqueles retidos na PCP e recebem a denominação de Proporção do Agregado Graúdo (Proporção AG). O material passante na PCP representam os agregados miúdos e são divididos em duas proporções: Proporção Graúda do Agregado Miúdo (Proporção GAF) e Proporção Fina dos Agregados Miúdos (Proporção FAF).

Para a determinação das duas frações de agregados miúdos, utiliza-se a Peneira de Controle Secundário (PCS), determinada pela Equação 2.

$$
P C S=P C P \times 0,22
$$

em que,

PCS: Peneira de Controle Secundário; e

$P C P$ : Peneira de Controle Primário.

Além das duas peneiras determinadas anteriormente, podemos citar ainda as seguintes peneiras: Peneira Média (PM), que é aquela mais próxima da metade do tamanho máximo nominal (TMN); e a Peneira de Controle Terciário (PCT), que é obtida através da multiplicação da Peneira de Controle Secundário (PCS) pelo fator de 0,22.

Com a determinação das frações de agregados e das peneiras de controle, podem-se determinar as proporções de agregados através das equações 3,4 e 5 .

Proporção $A G=\frac{(\% \text { passante na } P M-\% \text { passante na } P C P)}{(100 \%-\% \text { passante na } P M)}$

$$
\begin{aligned}
& \text { Proporção } G A F=\frac{(\% \text { passante na } P C S)}{(\% \text { passante na } P C P)} \\
& \text { Proporção } F A F=\frac{(\% \text { passante na } P C T)}{(\% \text { passante na } P C S)}
\end{aligned}
$$

Segundo Vavrik et al (2002), os valores para essas proporções de agregados devem estar nas faixas indicadas na Tabela 1 e misturas cujos valores dessas proporções não seguem as indicações desse autor, podem se tornar instáveis e apresentar dificuldade de compactação em campo, por exemplo.

\subsection{Massa Específica Escolhida de Agregado Graúdo}

Após a determinação da Massa Específica Solta e da Massa Específica Compactada do Agregado Graúdo através da AASHTO T-19 (AASHTO, 2009), passa-se à determinação da Massa Específica Escolhida do Agregado Graúdo, que nada mais é do que a seleção da quantidade de vazios da mistura. Essa escolha leva à determinação do volume de agregado graúdo e também do grau de intertravamento da mistura.

Com a determinação da massa específica escolhida, determina-se também se a mistura é graúda, onde o esqueleto é formado por agregado graúdo; ou se ela é miúda, quando a quantidade de agregado graúdo não é suficiente para formar o esqueleto e ele é formado por agregado miúdo (Vavrik et al., 2002).

As considerações para a determinação da Massa Específica Escolhida, que devem estar de acordo com a graduação que se deseja dar à mistura, são mostradas na Figura 1. Para misturas de graduação densa devem estar entre 95\% e $105 \%$ da massa específica solta. Valores entre $90 \%$ e $95 \%$ da massa específica solta devem ser evitados, porque possuem grande possibilidade de variação do grau de intertravamento dos agregados graúdos em campo. Já os valores acima de $105 \%$ devem ser evitados devido à maior possibilidade de degradação do agregado e pela dificuldade de compactação em campo.

\section{MATERIAIS E MÉTODOS}

Para avaliar a viabilidade de emprego do Método Bailey em misturas asfálticas, foram elaboradas duas misturas do tipo Concreto Asfáltico: uma cujo esqueleto foi dosado pelo Método Tradicional das tentativas e outra em que foi utilizado o Método Bailey para a determinação do esqueleto mineral. Ainda foram elaboradas mais duas misturas: uma com alteração em 0,2 na Proporção AG e outra com alteração de 5\% na Massa Específica Escolhida, ambas partindo da primeira solução que o método Bailey indicou. 


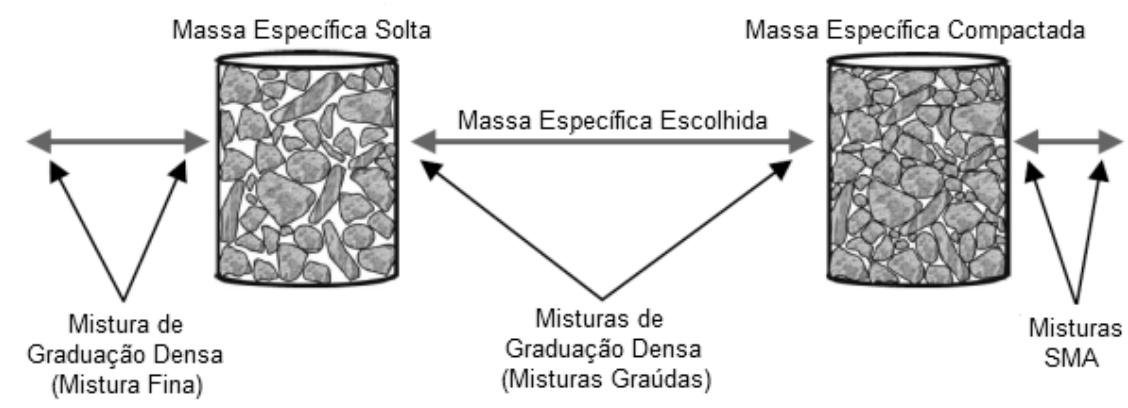

Figura 1. Seleção da Massa Específica dos Agregados Graúdos (VAVRIK et al., 2002)

\subsection{Materiais}

Para a elaboração das misturas foi utilizado o agregado proveniente de uma única fonte e denominados, comercialmente, de "Brita 1", "Brita 0" e "Areia Industrial", fornecidos pela pedreira "Pedra Sul”, localizada na BR 040, próximo ao $\mathrm{km} 800$. A distribuição granulométrica desses materiais encontra-se na Figura 2.

O material utilizado como ligante asfáltico nessa pesquisa é o CAP 50/70, fabricado pela REDUC (Refinaria Duque de Caxias - Rio de Janeiro), por ser o tipo mais usual em obras de pavimentação asfáltica na região.

Para a elaboração da mistura de agregados, inicialmente dosou-se uma mistura buscando enquadrá-la na especificação do DNIT, Pavimentos Flexíveis - Concreto Asfáltico -
Especificação de Serviço (DNIT, 2006) e nas especificações SUPERPAVE. O proporcionamento dos agregados foi determinado através do método das tentativas e foi denominada Mistura Tradicional.

A partir dessa mistura Tradicional, foram feitas modificações seguindo as sugestões do Método Bailey e foi obtida uma nova mistura, designada de Mistura Bailey. Seguindo as recomendações do Método, foram modificadas algumas características da Mistura Bailey resultando em uma mistura com a proporção $\mathrm{AG}$ aumentada em 0,2 (designada de Mistura Bailey $\mathrm{AG}+0,2$ ) e em uma mistura com aumento de $5 \%$ da massa específica escolhida (chamada de Mistura Bailey MEE + 5\%). As composições granulométricas resultantes encontram-se na Tabela 2.

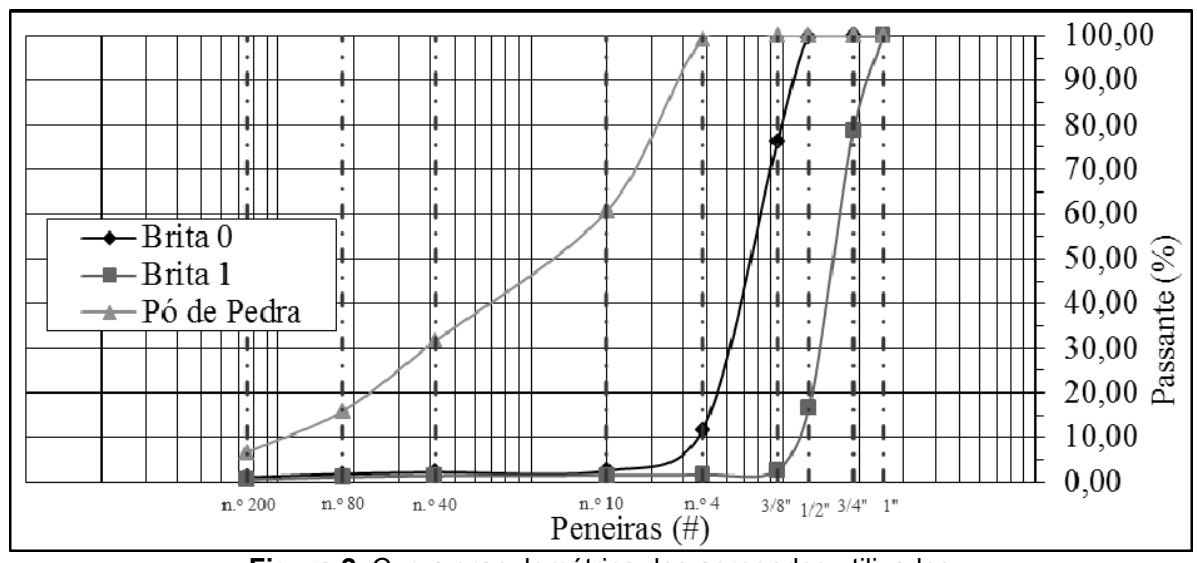

Figura 2. Curva granulométrica dos agregados utilizados

Tabela 2. Composição granulométrica e composição de agregados das misturas estudadas

\begin{tabular}{|c|c|c|c|c|c|}
\hline \multirow{2}{*}{ Agregado } & & \multicolumn{4}{|c|}{ Composição de agregados (\%) } \\
\hline & & Tradicional & Bailey & Bailey MEE + 5\% & Bailey $A G+0,2$ \\
\hline \multicolumn{2}{|l|}{ Brita 1} & 10,0 & 21,1 & 21,5 & 20,6 \\
\hline \multicolumn{2}{|l|}{ Brita 0} & 43,0 & 29,0 & 32,0 & 29,5 \\
\hline \multicolumn{2}{|c|}{ Pó de Pedra } & 47,0 & 49,9 & 46,5 & 49,9 \\
\hline \multirow{2}{*}{\multicolumn{2}{|c|}{ Peneiras }} & \multicolumn{4}{|c|}{ Composição Granulométrica das Misturas Estudadas } \\
\hline & & Tradicional & Bailey & Bailey $M E E+5 \%$ & Bailey $A G+0,2$ \\
\hline$m m$ & $\mathrm{pol} / \mathrm{n}^{\circ}$ & \multicolumn{4}{|l|}{$\%$ Passante } \\
\hline 38,1 & $11 / 2^{\prime \prime}$ & 100,0 & 100,0 & 100,0 & 100,0 \\
\hline 25,4 & $1 "$ & 100,0 & 100,0 & 100,0 & 100,0 \\
\hline 19,05 & 3/4" & 97,9 & 95,5 & 95,4 & 95,6 \\
\hline 12,7 & $1 / 2^{\prime \prime}$ & 91,6 & 82,4 & 82,0 & 82,8 \\
\hline 9,5 & $3 / 8^{\prime \prime}$ & 80,0 & 72,6 & 71,5 & 72,9 \\
\hline 4,8 & $\mathrm{n}^{\circ} 4$ & 51,7 & 53,2 & 50,1 & 53,2 \\
\hline 2,0 & $\mathrm{n}^{\circ} 10$ & 29,8 & 31,3 & 29,4 & 31,3 \\
\hline 0,42 & $\mathrm{n}^{\circ} 40$ & 15,9 & 16,7 & 15,7 & 16,7 \\
\hline 0,18 & $\mathrm{n}^{\circ} 80$ & 8,4 & 8,7 & 8,3 & 8,7 \\
\hline 0,075 & $\mathrm{n}^{\circ} 200$ & 3,7 & 3,8 & 3,6 & 3,8 \\
\hline
\end{tabular}


Tabela 3. Parâmetros granulométricos das misturas utilizadas

\begin{tabular}{llllll}
\hline & Mistura & & & \\
\cline { 2 - 5 } Parâmetro & $\begin{array}{l}\text { Desejável } \\
\text { (VAVRIK et al, 2002) }\end{array}$ & Tradicional & Bailey & $\begin{array}{l}\text { Mailey } \\
\text { MEE } \%\end{array}$ & Bailey AG $+0,2$ \\
\hline Massa Específica & & & & & \\
Escolhida & $95 \%-105 \%$ & - & $98 \%$ & $103 \%$ & $98 \%$ \\
Proporção AG & $0,60-0,75$ & 1,42 & 0,71 & 0,75 & 0,73 \\
Proporção GAF & $0,35-0,50$ & 0,48 & 0,49 & 0,49 & 0,49 \\
Proporção FAF & $0,35-0,50$ & 0,52 & 0,52 & 0,52 & 0,52 \\
\hline
\end{tabular}

Ao observar a Tabela 2, constata-se que a mistura Tradicional não se adequava aos parâmetros granulométricos do Método Bailey, principalmente no que diz respeito à proporção de agregados graúdos.

Na Tabela 3 encontram-se os parâmetros granulométricos indicados pelo Método Bailey para as misturas estudadas. Como se pode observar, todas as misturas estudadas apresentaram proporção de finos do agregado fino superior ao valor desejável. Isto se deve à presença de finos em todos os agregados, inclusive nos graúdos, que não foram descartados no momento da determinação e nem na elaboração das misturas.

\subsection{Métodos}

Para a determinação dos teores de projeto, foi utilizada a metodologia SUPERPAVE e o resultado final para os teores de projeto encontram-se na Tabela 4. Esses teores foram obtidos para uma condição de vazios de $4 \%$, com variação mínima de $\pm 0,2 \%$, conforme recomenda tal metodologia. Os demais parâmetros volumétricos atenderam as recomendações da Metodologia SUPERPAVE.

Tabela 4. Teor de projeto das misturas estudadas

\begin{tabular}{ll}
\hline Misturas & Teor de Projeto \\
\hline Tradicional & $5,14 \%$ \\
Bailey & $4,22 \%$ \\
Bailey MEE $+5 \%$ & $4,66 \%$ \\
Bailey AG $+0,2$ & $4,66 \%$ \\
\hline
\end{tabular}

Após a determinação dos teores de projeto, foram confeccionados os corpos de prova utilizados para os ensaios mecânicos. Foram realizados ensaios de Resistência à Tração, Módulo de Resiliência, Vida de Fadiga e Deformação Permanente. Os resultados apresentados, representam a média de 6 réplicas para cada ensaio.

\section{RESULTADOS E ANÁLISES}

\subsection{Resistência à Tração e Módulo de Resiliência}

Os ensaios de Resistência à Tração foram realizados conforme norma NBR 15087 - Misturas asfálticas - Determinação da Resistência à Tração por compressão diametral (ABNT, 2004) e os resultados encontrados para as misturas estudadas encontram-se na Tabela 5 e na Figura 3. Os valores apresentados nesta tabela compreendem a média (6 réplicas) dos valores encontrados para cada mistura.

Os maiores valores para a Resistência à Tração foram encontrados nas misturas que utilizaram o Método Bailey para a determinação do esqueleto mineral, quando comparadas à mistura Tradicional. Uma vez que o Método Bailey tem por objetivo proporcionar um intertravamento mais eficiente do esqueleto mineral, esse resultado era esperado, já que este intertravamento gera misturas mais resistentes.

Comparando-se as misturas em que se utilizou o Método Bailey, observa-se que as misturas Bailey e Bailey AG + 0,2 apresentaram resultados próximos (1,72 $\mathrm{MPa}$ e 1,82 $\mathrm{MPa})$, uma vez que essas misturas apresentam composições

Tabela 5. Resultados da Resistência à Tração (MPa), Módulo de Resiliência (MPa) e Relação MR/RT para as misturas estudadas

\begin{tabular}{llll}
\hline Mistura & $\begin{array}{l}\text { Resistência à Tração } \\
(\boldsymbol{M P a})\end{array}$ & $\begin{array}{l}\text { Módulo de Resiliência } \\
(\boldsymbol{M P a})\end{array}$ & MR/RT \\
\hline Tradicional & 1,47 & 5232 & 3559 \\
Bailey & 1,72 & 6957 & 4045 \\
Bailey MEE $+5 \%$ & 2,06 & 10061 & 4884 \\
Bailey AG + 0,2 & 1,82 & 7998 & 4395 \\
\hline
\end{tabular}

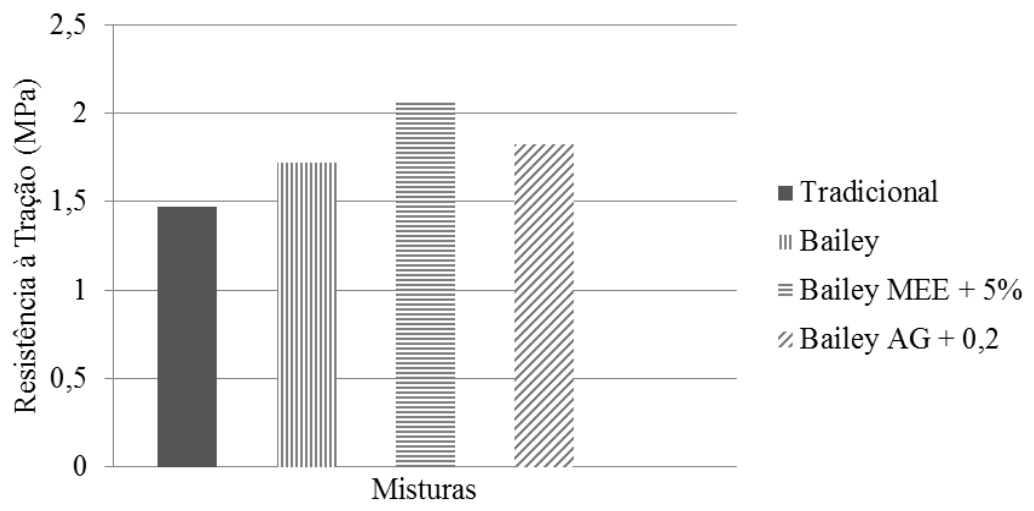

Figura 3. Resistência à Tração (MPa) para as misturas estudadas 


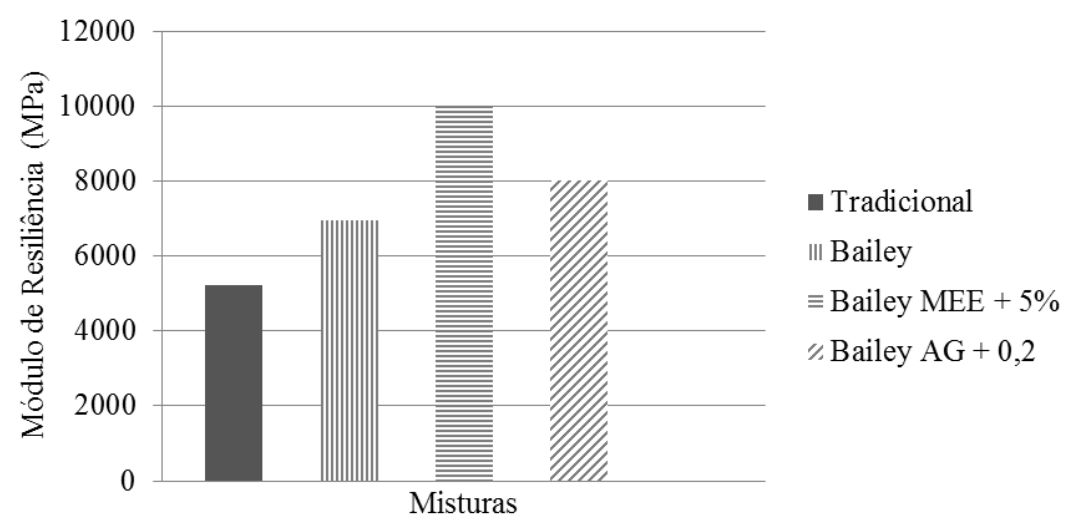

Figura 4. Módulo de Resiliência (MPa) para as misturas estudadas

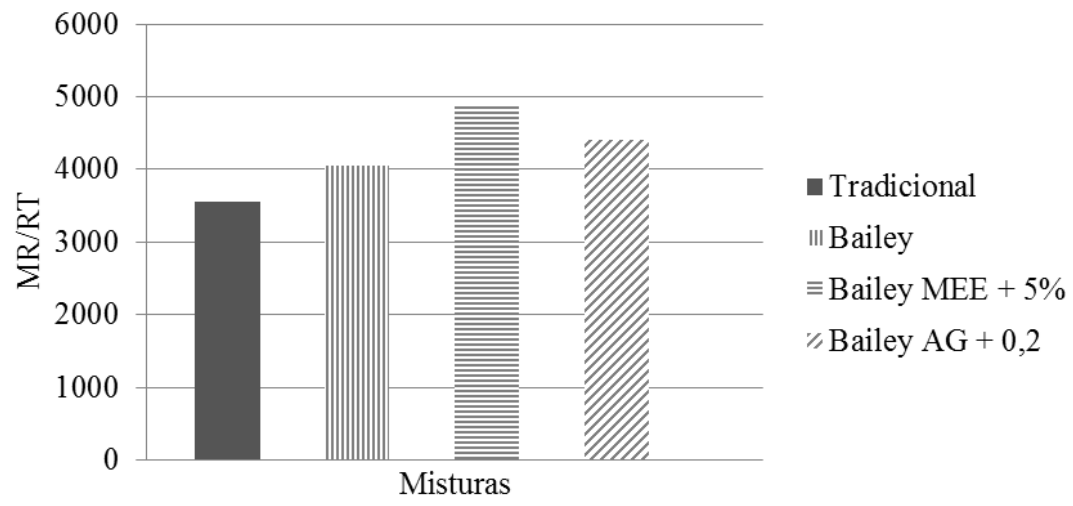

Figura 5. Relação MR/RT para as misturas estudadas

granulométricas muito parecidas. Com relação à mistura Bailey MEE + 5\%, observa-se um aumento de 40,1\% com relação à mistura Tradicional e de 19,8\% com relação à mistura Bailey. $\mathrm{O}$ aumento da Massa Específica escolhida gerou um aumento de 0,4 na proporção $A G$, que conduziu a um aumento da quantidade de agregado graúdo, gerando um maior intertravamento do agregado graúdo e, consequentemente, maior Resistência à Tração.

Os ensaios de Módulo de Resiliência foram realizados conforme a norma DNIT-ME 135/2010 - Pavimentação Asfáltica - Misturas Asfálticas - Determinação do Módulo de Resiliência - Método de Ensaio (DNIT, 2010). Os resultados encontrados para as misturas estudadas encontram-se na Tabela 5 e na Figura 4. O valor apresentado nesta tabela compreende a média dos valores encontrados para cada mistura.

Observa-se que os resultados obtidos para o Módulo de Resiliência apresentaram a mesma tendência que os resultados obtidos para a RT, onde a mistura Bailey MEE $+5 \%$ apresentou os maiores valores, as misturas Bailey e Bailey $\mathrm{AG}+0,2$ apresentaram valores próximos (6957 MPa e $7998 \mathrm{MPa}$ ), mas, ainda assim, acima dos valores obtidos para a mistura tradicional (5232 $\mathrm{MPa})$.

As misturas proporcionadas através do Método Bailey apresentam maior rigidez em comparação à mistura tradicional, ou seja, valores mais altos para o Módulo de Resiliência. Ainda assim, não se pode afirmar que essas misturas apresentem melhor desempenho, já que as misturas devem apresentar flexibilidade suficiente para suportar as deformações ao mesmo tempo em que devem apresentar Resistência à Tração para evitar rupturas, além de terem rigidez compatível com a dos materiais das demais camadas do pa- vimento.

Com os valores obtidos para a RT e o MR, foram calculadas as relações MR/RT das misturas estudadas. Os valores encontrados estão na Tabela 5 e na Figura 5.

A relação entre $\mathrm{MR} / \mathrm{RT}$ indica a compatibilidade entre a rigidez e a Resistência à Tração da mistura asfáltica. Através da análise dos valores encontrados, podemos observar que os maiores valores para a relação MR/RT se deram nas misturas mais rígidas, cujo Módulo de Resiliência é maior. As misturas rígidas, com MR elevado, necessitam de altos valores de RT, devido à concentração de esforços em seu interior (Morilha Junior, 2004).

Alguns pesquisadores acreditam que menores valores da relação $\mathrm{MR} / \mathrm{RT}$ resultem em misturas com maior vida de fadiga, mas a relação MR/RT foi criada com a finalidade de atender as universidades que não dispunham de equipamento necessário para a realização do ensaio de Módulo de Resiliência (Lopes et. al, 2008). O menor valor para a relação MR/RT foi encontrado na mistura Tradicional (3559).

Em estudos realizados por Vale (2007), não houve correlação evidente entre o valor da relação e dos valores encontrados para a Vida de Fadiga. Sendo assim, os resultados encontrados para essa relação devem ser analisados para cada caso.

\subsection{Vida de Fadiga}

O ensaio de fadiga utilizado foi o de tensão controlada que consiste na aplicação de carregamentos cíclicos, com duração de 0,1 segundo e recuperação de 0,9 segundos, com tensões que variaram entre $40 \%$ e $15 \%$ da Resistência à Tração e carga aplicada em forma de pulsos, até a ruptura do corpo de prova. 


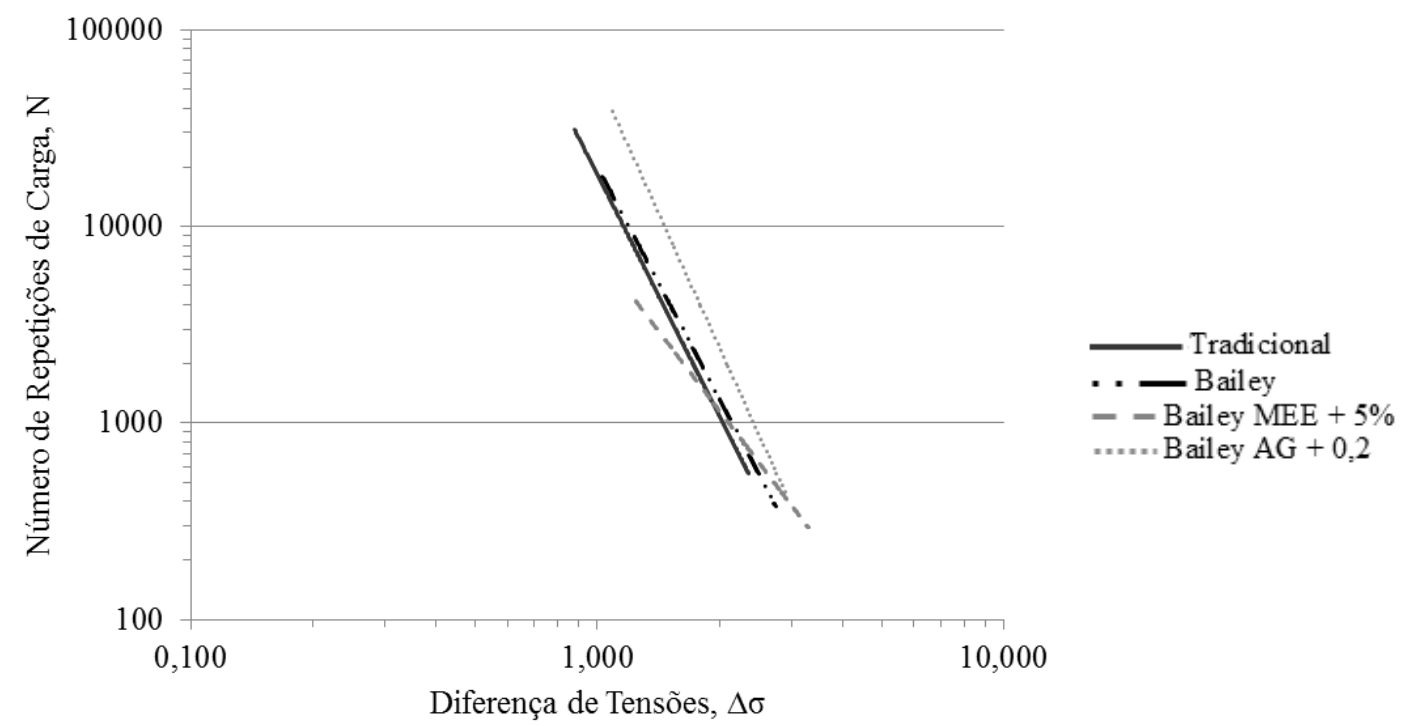

Figura 6. Número de Repetições $(\mathrm{N})$ x Diferença de Tensões $(\Delta \sigma)$ para as misturas estudadas

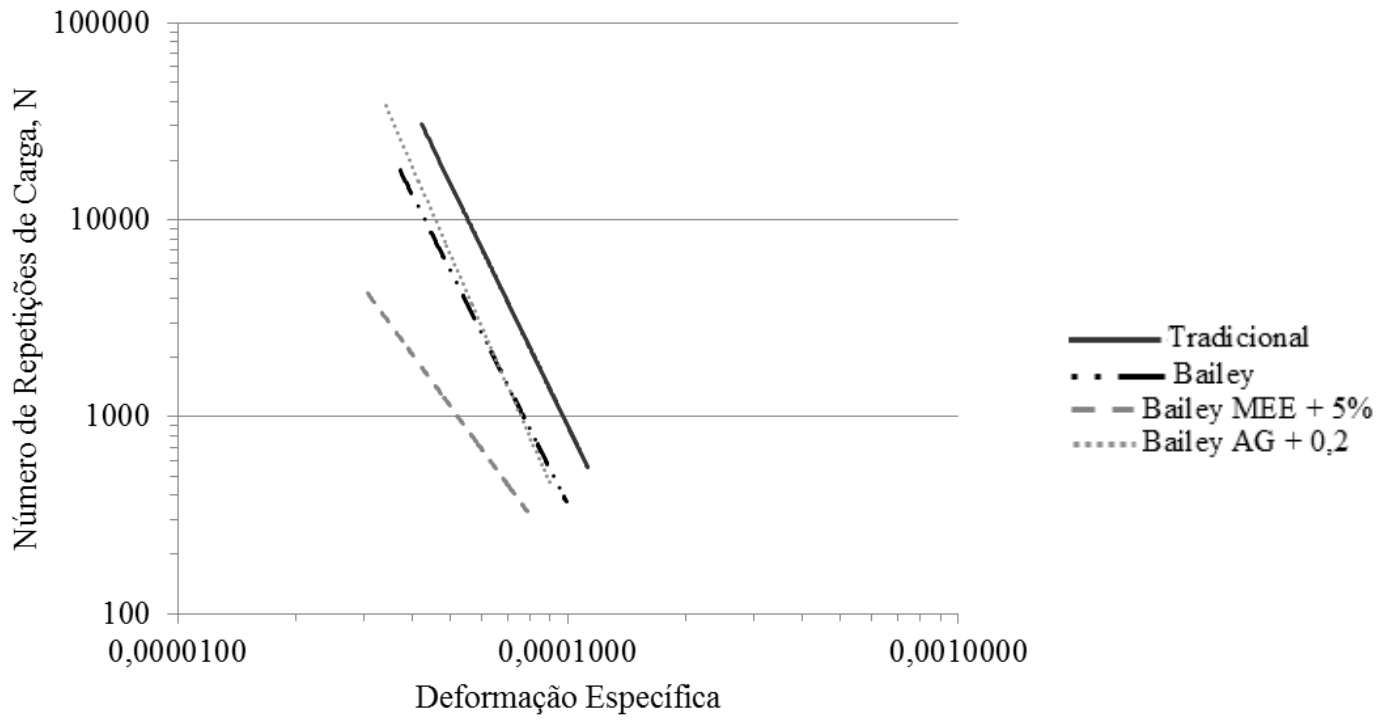

Figura 7. Número de Repetições $(\mathrm{N}) \times$ Deformação Específica $(\varepsilon)$ para as misturas estudadas

Os resultados encontrados para as misturas estudadas encontram-se nas Figuras 6 e 7 e descrevem a vida de fadiga através das relações "Número de Repetições de Carga" $\mathrm{x}$ "Diferença de tensões" e "Número de Repetições de Carga" x "Deformações Específicas".

As equações obtidas através de regressão linear para as curvas demonstradas na Figura 6 são:

Mistura Tradicional:

$$
\mathrm{N}=18349 \cdot \Delta \sigma^{-4,094}, \mathrm{R}^{2}=0,9719
$$

Mistura Bailey:

$$
\mathrm{N}=20173 \cdot \Delta \sigma^{-3,941}, \mathrm{R}^{2}=0,9192
$$

Mistura Bailey MEE $+5 \%$ :

$$
\mathrm{N}=7511,3 \cdot \Delta \sigma^{-2,713}, \mathrm{R}^{2}=0,8838
$$

Mistura Bailey AG + 0,2:

$$
\mathrm{N}=56806 \cdot \Delta \sigma^{-4,566}, \mathrm{R}^{2}=0,9783
$$

As equações obtidas para as curvas demonstradas na Figura 7 são:
Mistura Tradicional:

$$
\mathrm{N}=4 \cdot \mathrm{E}^{-14} \cdot \varepsilon^{-4,092}, \mathrm{R}^{2}=0,9726
$$

Mistura Bailey:

$$
\mathrm{N}=6 \cdot \mathrm{E}^{-14} \cdot \varepsilon^{-3,943}, \mathrm{R}^{2}=0,9201
$$

Mistura Bailey MEE + 5\%:

$$
\mathrm{N}=3 \cdot \mathrm{E}^{-9} \cdot \varepsilon^{-2,706}, \mathrm{R}^{2}=0,8853
$$

Mistura Bailey AG + 0,2:

$$
\mathrm{N}=2 \cdot \mathrm{E}^{-16} \cdot \varepsilon^{-4,562}, \mathrm{R}^{2}=0,9778
$$

A análise da Vida de Fadiga através da variação de diferença de tensões $(\Delta \sigma)$ demonstra que a mistura Bailey AG $+0,2$ apresentou os melhores resultados, enquanto a mistura Bailey MEE $+5 \%$ apresentou os piores resultados. Sob a ótica da diferença de tensões, a mistura que apresentou o maior valor de MR/RT (Bailey MEE + 5\%) foi a que apresentou a menor vida de fadiga. Com relação às misturas Tradicional e Bailey, os valores obtidos foram muito pró- 
Tabela 6. Estruturas hipotéticas para análise da vida de fadiga

\begin{tabular}{llllll}
\hline Estrutura & Camada & Espessura $(\mathbf{c m})$ & Coef. Poisson & MR $(\boldsymbol{M P a})$ & MR $(\boldsymbol{p s i})$ \\
\hline & Capa & 10,0 & 0,30 & Variável & MR \\
& Base & 20,0 & 0,34 & 340 & 51.000 \\
& Sub-base & 20,0 & 0,38 & 210 & 31.500 \\
1 & Subleito & Semi-infinito & 0,42 & 85 & 12.750 \\
\hline & Capa & 7,5 & 0,30 & Variável & MR \\
& Base & 20,0 & 0,30 & 450 & 67.500 \\
2 & Subleito & Semi-infinito & 0,40 & 60 & 9.000 \\
\hline
\end{tabular}

Tabela 7. Comparação da vida de fadiga das misturas estudadas

\begin{tabular}{|c|c|c|c|c|c|}
\hline Misturas & $M R(K P a)$ & $\begin{array}{l}\text { Estrutura } 1 \\
\sigma t(M P a)\end{array}$ & $\sigma c(M P a)$ & $\Delta \sigma(M P a)$ & $N$ \\
\hline Tradicional & 5232 & 0,997 & $-0,154$ & 1,151 & 10317 \\
\hline Bailey & 6957 & 1,180 & $-0,135$ & 1,315 & 6856 \\
\hline Bailey MEE + 5\% & 10061 & 1,435 & $-0,113$ & 1,548 & 2295 \\
\hline \multirow[t]{2}{*}{ Bailey AG + 0,2 } & 7998 & 1,273 & $-0,127$ & 1,400 & 12223 \\
\hline & & Estrutura 2 & & & \\
\hline Misturas & $M R(\mathrm{KPa})$ & $\sigma t(M P a)$ & $\sigma c(M P a)$ & $\Delta \sigma(M P a)$ & $N$ \\
\hline Tradicional & 5232 & 1,060 & $-0,228$ & 1,288 & 6510 \\
\hline Bailey & 6957 & 1,332 & $-0,203$ & 1,535 & 3726 \\
\hline Bailey MEE + 5\% & 10061 & 1,729 & $-0,173$ & 1,902 & 1312 \\
\hline Bailey $\mathrm{AG}+0,2$ & 7998 & 1,476 & $-0,191$ & 1,667 & 5508 \\
\hline
\end{tabular}

ximos.

Analisando-se a Vida de Fadiga por meio da variação da deformação específica, observa-se que a mistura Tradicional apresentou os melhores resultados e a Mistura Bailey MEE $+5 \%$ apresentou, novamente, os piores valores. As mistura Bailey e Bailey $\mathrm{AG}+0,2$ apresentaram resultados muito próximos entre si e valores intermediários com relação às duas misturas citadas anteriormente (Tradicional e MEE + 5\%).

A mistura Tradicional apresentou os menores resultados para a relação $\mathrm{MR} / \mathrm{RT}$ e também os melhores resultados para a Vida de Fadiga. A mistura Bailey MEE $+5 \%$ obteve o maior valor de MR/RT e a menor Vida de Fadiga.

No entanto, a análise das curvas de fadiga não deve ser feita de forma simples e direta sobre as curvas de diferença de tensões e deformação específica conforme descrito. Deve-se levar em consideração o Módulo de Resiliência do material uma vez que é a sua viscoelasticidade que influencia a resistência ao fadigamento.

Com a finalidade de melhor entender a influência das alterações de granulometria indicadas pela metodologia Bailey na vida de fadiga das misturas estudadas optou-se por fazer uma análise de tensões em duas estruturas hipotéticas, relacionadas na Tabela 6 . Foram determinadas as diferenças de tensões na fibra inferior da camada de revestimento asfáltico sob um carregamento de rodas duplas em duas estruturas de pavimentos diferentes: uma esbelta e mais flexível e outra menos espessa e menos flexível.

Para esta análise nas duas estruturas hipotéticas foi utilizado o programa ELSYM5 e foi considerado um carregamento de rodas duplas, separadas por uma distância de $33,3 \mathrm{~cm}$, com uma pressão de carregamento de $5,6 \mathrm{~kg} / \mathrm{cm}^{2}$ cada, uma carga por roda de $2050 \mathrm{Kg}$, aplicada numa área circular de 10,8 cm de raio. A definição das duas estruturas hipotéticas com suas espessuras, coeficiente de Poisson e Módulo de Resiliência para as camadas podem ser vistas na tabela 6 e foram baseadas em análises semelhantes do trabalho de NOVADUTRA (2005) e Ildefonso (2007).
Para cada estrutura foi feita uma simulação da condição experimental descrita anteriormente sendo que na camada de revestimento foram utilizados os valores de MR de cada uma das quatro misturas estudadas neste trabalho. As tensões geradas pelas condições experimentais foram calculadas pelo programa ELSYM5. A situação mais desfavorável quanto às tensões de tração ocorreram no ponto sob a roda e na fibra inferior do revestimento.

Com os valores de Tensões (tração e compressão) calculados na fibra inferior do revestimento foram obtidos as diferenças de tensões e utilizadas nos modelos de cada material (equações de 6 a 9). A tabela 7 mostra os resultados desta análise, destacando as tensões nos pontos críticos, a diferença de tensões e o numero de ciclos (N) que cada mistura suportaria nas duas situações estruturais analisadas.

$\mathrm{Na}$ estrutura 1, a mistura Bailey $\mathrm{AG}+0,2$ foi a que apresentou o maior número de repetições de carga $(\mathrm{N})$, seguida da mistura Tradicional, portanto as melhores expectativas quanto a vida de fadiga. A mistura Bailey MEE $+5 \%$ foi a que apresentou o pior resultado (menor $\mathrm{N}$ ) quanto à vida de fadiga. Nesta estrutura percebe-se que ao usar uma mistura com maior valor de MR/RT (Bailey MEE $+5 \%$ ), portanto mais rígida, o reflexo na vida de fadiga é maior.

$\mathrm{Na}$ estrutura 2 as misturas Tradicional e Bailey AG +0,2 foram novamente as que apresentaram maiores números de repetições de carga $(\mathrm{N})$, sendo a primeira ligeiramente maior que a segunda, invertendo as posições quando comparada com a estrutura anterior. Nesta estrutura, novamente a mistura Bailey MEE $+5 \%$ foi a que apresentou o menor resultado para o número de repetições de carga $(\mathrm{N})$. A alta rigidez também foi prejudicial neste caso.

Desta análise pode-se perceber que pequenas alterações na granulometria podem influenciar no desempenho quanto a vida de fadiga e que cada mistura deve ser determinada (escolhida) de acordo com a estrutura na qual será submetida. 


\subsection{Análise da Compactação Giratória}

Analisou-se a Compactação Giratória através dos parâmetros obtidos com as curvas geradas pelo compactador giratório (número de giros x \% Gmm), o Compaction Densification Index (CDI) e o Traffic Densification Index (TDI), utilizados para tentar definir melhor um projeto de mistura asfáltica.

O Compaction Densification Index (CDI) é definido como a área sob a curva de densificação obtida com o SGC, a partir do oitavo giro $(\mathrm{N}=8)$ até $92 \%$ da $\mathrm{Gmm}$. Este índice pode ser relacionado ao trabalho aplicado pela acabadora ou pelos rolos para compactar a mistura na densidade requerida para a construção.

O Traffic Densification Index (TDI) representa a quantidade de esforços requeridos para densificar a mistura entre $92 \%$ e $98 \%$ do Gmm, sendo definido pela área sobre a curva entre estes dois pontos. Esse índice se justifica pelo fato da mistura continuar a se densificar sob a ação da carga do tráfego, a 92\% da Gmm (MARQUES et. al, 2009). Neste trabalho, porém, foi utilizado o TDI modificado, que é obtido através da área sobre a curva entre $92 \%$ e $96 \%$ do Gmm, que representa o valor usual de compactação durante a dosagem.

Os valores obtidos para as misturas estudadas encontram-se na Tabela 8.

Tabela 8. Parâmetros CDI e TDI

\begin{tabular}{llr}
\hline Mistura & CDI & \multicolumn{1}{c}{ TDI } \\
\hline Tradicional & 185,0 & 157,3 \\
Bailey & 238,0 & 89,2 \\
Bailey MEE $+5 \%$ & 208,2 & 121,2 \\
Bailey AG $+0,2$ & 121,7 & 162,8 \\
\hline
\end{tabular}

A utilização dos parâmetros de compactação CDI e TDI nos estudos de misturas asfálticas tem por objetivo auxiliar na escolha de misturas que sejam suficientemente trabalháveis durante a construção do revestimento e que sejam, ao mesmo tempo, suficientemente fortes para resistirem à densificação sob o tráfego. Assim sendo, misturas com menores valores de CDI tendem a se densificar melhor inicialmente em campo e altos valores de TDI são mais desejáveis por indicar a necessidade de maior volume de tráfego para se densificar na fase final da vida do revestimento (BAHIA et al, 1998).

De acordo com os resultados da Tabela 8, observa-se que a mistura tradicional foi a que apresentou os valores simultâneos para o CDI e TDI mais próximos da recomendação de Bahia et al (1998), quando se comparam as misturas estudadas entre si (menor CDI e maior TDI).

$\mathrm{Na}$ realidade, a mistura que apresentou comparativamente o menor valor de CDI e maior valor de TDI foi a mistura Bailey $\mathrm{AG}+0,2$. Contudo, um esclarecimento deve ser feito. Durante o processo de compactação desta mistura, ocorreu um problema técnico (a fonte do PC vinculado ao Compactador Giratório queimou) e até que o problema fosse solucionado levou-se 2 horas. Com isso, o início da compactação dos corpos de prova atrasou em 2 horas.

Acredita-se que este tempo a mais na estufa (totalizando 4 horas ao invés das 2 horas utilizadas para as outras misturas), tenha sido o responsável pela melhor densificação da mistura, semelhante ao que ocorre na prática, quando a mistura asfáltica é compactada com temperaturas próximas ao limite superior de operação. Como este fato ocorreu somen- te nesta mistura e para que não interferisse na comparação com as demais misturas, resolveu-se desconsiderar a Mistura Bailey $\mathrm{AG}+0,2$ desta análise. Acredita-se que não haverá prejuízo nas comparações, uma vez que esta mistura é muito parecida com a mistura Bailey.

Ao analisar as outras três misturas, observa-se que as misturas Bailey e Bailey MEE $+5 \%$ apresentam alto valores tanto para o CDI e baixos valores para o TDI em comparação com a mistura tradicional. Este fato mostra que as misturas cujo esqueleto mineral é dosado pelo Método Bailey tenderão a apresentar maior dificuldade de compactação inicial em campo e rápida densificação com o tráfego.

Esta era a expectativa inicial, uma vez que o esqueleto mineral proporcionado pelo Método Bailey é mais intertravado que o da mistura Tradicional, o que provocará uma dificuldade de compactação inicial no campo. Misturas densas como a Tradicional utilizada neste estudo tem maior facilidade de compactação devido à distribuição granulométrica contínua de seu esqueleto mineral.

Portanto, quanto à densificação final, que é avaliada através do parâmetro TDI, não se pode afirmar que as misturas com o proporcionamento de agregados através do Método Bailey apresentam resultados que indicam dificuldade de densificação. Os altos valores esperados para o TDI (acima de 250, segundo Nascimento (2008)), referem-se à alternativa de obtenção do parâmetro aos $98 \%$ da Gmm. Os corpos de prova utilizados neste trabalho foram compactados até $96 \%$ da Gmm, segundo exigência do Método SUPERPAVE. Dessa forma, os valores obtidos são inferiores àqueles que seriam obtidos caso os corpos de prova fossem compactados até o limite de $98 \%$ da Gmm.

Para efeito da compactação/densificação inicial, as misturas Bailey apresentam maior dificuldade, porém esta expectativa só poderá ser confirmada durante a execução de trechos experimentais, já que este estudo de laboratório visa mostrar esta característica da mistura ainda na fase de dosagem.

\section{CONSIDERAÇÕES FINAIS}

Com base nos resultados obtidos através das misturas estudadas, foi possível obter algumas conclusões. No que diz respeito à Resistência à Tração, a mistura dosada pelo Método Tradicional apresentou menor valor do que os que foram encontrados para as misturas em que se utilizou o método Bailey para a determinação do esqueleto mineral. Esse resultado já era esperado, uma vez que um dos benefícios do método Bailey é proporcionar o intertravamento mais eficiente das misturas.

Com relação ao Módulo de Resiliência, percebe-se que a tendência observada na Resistência à Tração se manteve, com os maiores valores obtidos nas misturas em que foi utilizado o Método Bailey, comprovando o intertravamento mais eficiente das misturas. Observa-se ainda que os maiores valores de Módulo de Resiliência correspondem aos maiores valores de Resistência à Tração, uma vez que misturas com maiores valores de Resistência à Tração necessitam de Módulo de Resiliência maiores, para resistir às tensões a que a mistura está sujeita.

Analisando-se a relação MR/RT, observa-se que os maiores valores obtidos para esta relação encontram-se nas misturas que utilizaram o método Bailey, indicando uma boa capacidade estrutural dessas misturas, uma vez que pa- 
ra valores elevados de MR é desejável que se tenha maiores valores de RT.

Para a análise da Vida de Fadiga através das curvas obtidas ("Número de Repetições de Carga" x "Diferença de tensões" e "Número de Repetições de Carga" x "Deformações Específicas"), mostraram que os valores obtidos para o desempenho da mistura Bailey $\mathrm{AG}+0,2$ são superiores à mistura tradicional, especialmente para as diferenças de tensões abaixo de 2,0 Mpa.

Das análises que levaram em conta a elasticidade das camadas em estruturas hipotéticas na avaliação da vida de fadiga das misturas estudadas, foi observado que a mistura Bailey MEE $+5 \%$ foi a que apresentou menor desempenho quanto ao fadigamento uma vez que é a mistura com maior relação $\mathrm{MR} / \mathrm{RT}$.

A análise dos parâmetros de densificação CDI e TDI para a previsão de comportamento in situ indicaram que a mistura Tradicional deverá apresentar uma facilidade maior de para se densificar na fase inicial da vida de projeto (entre a aplicação e a compactação no campo), uma vez que apresentou menor valor para o CDI e valores elevados para o TDI.

Para as misturas proporcionadas através do método Bailey, observa-se que essas misturas estão sujeitas a uma maior dificuldade de compactação na fase inicial, o que era esperado em função do maior intertravamento dos agregados, mostrado pelos outros parâmetros analisados. Com relação à densificação final, o parâmetro de previsão desse comportamento, TDI, não pode ser considerado neste trabalho.

Finalmente, analisando-se todos os resultados e restringindo-se às limitações que o experimento apresentou, podese dizer que a mistura dosada utilizando o Método Bailey para proporcionamento dos agregados apresentou desempenho ligeiramente melhor que aquela dosada pelo Método Tradicional. Sendo assim, faz-se a ressalva de que as vantagens mostradas pelo Método Bailey são restrita às condições em que o experimento foi concebido, não podendo ser generalizadas.

Como sugestão, destaca-se a necessidade de se analisar em futuras pesquisas a influência de outras variáveis, como o tipo de agregado, o teor de finos, o teor de ligante, o tipo de ligante e o tipo de compactação.

\section{REFERÊNCIAS}

AASHTO (2009) Standard Method of Test for Bulk Density ("Unit Weight") and Voids in Aggregate American Association of State Highway and Transportation Officials, AASHTO T19, Washington, D. C.

ABNT (2004) NBR 15087 - Misturas asfálticas - Determinação da resistência à tração por compressão diametral. Associação Brasileira de Normas Técnicas, Rio de Janeiro.

Asphalt Institute (1989). The Asphalt Handbook. Lexington, Manual Series $\mathrm{N}^{\circ} 4(\mathrm{MS}-4)$.

Bahia, H. U., T. P. Frieme, P. A. Peterson et al (1998) Optimization of Constructibility and Resistence to Traffic: A New Design Approach for HMA Using the SUPERPAVE Compactor. Journal of the Association of Asphalt Paving Technologists, volume 67, p. $189-232$.

Cunha, M. B (2004) Avaliação do Método de Bailey de Seleção Granulométrica de Agregados para Misturas Asfálticas. Dissertação (Mestrado). Escola de Engenharia de São Carlos, Universidade de São Paulo. São Carlos.

DNIT (2006) Pavimentos Flexiveis - Concreto Asfáltico. Departamento Nacional de Infraestrutura de Transporte, Especificação de Serviço DNIT - ES 031/2006.
DNIT (2010) Pavimentação Asfáltica - Misturas Asfálticas - Determinação do Módulo de Resiliência - Método de Ensaio. Departamento Nacional de Infraestrutura de Transporte, Especificação de Serviço DNIT - ME 135/2010.

Gouveia, L. T (2002) Avaliação do Ensaio de Angularidade do Agregado Fino (FAA) da Especificação SUPERPAVE. Dissertação (Mestrado). Escola de Engenharia de São Carlos, Universidade de São Paulo, São Carlos.

Ildefonso, J. S (2007) Análise da Viabilidade Técnica da Utilização do Copolímero Etileno Acetato de Vinila (EVA) Descartado Pela Indústria Calçadista em Misturas Asfálticas (Processo a Seco). Dissertação (Mestrado). Escola de Engenharia de São Carlos, Universidade de São Paulo. São Carlos.

Lopes, M. M., F. C. Onofre, A. C. do Vale e J. B. Soares (2008) Estudo Laboratorial de Misturas Asfálticas SMA 12,5mm Dosadas com Diferentes tipos de Ligantes Asfálticos. In: XV Congresso Panamericano de Engenharia de Trânsito e Transporte (PANAM), 2008, Cartagena de Indias, Colombia. XV Congresso Panamericano de Engenharia de Trânsito e Transporte (PANAM).

Marques, G. L. O., T. T. Ramiro e L. M. G. Motta (2009) Influência dos Índices de Energia de Densificação nos Valores de Módulo de Resiliência de Misturas Asfálticas. In: XV Congresso IberoLatinoAmerincano do Asfalto, 2009, Lisboa. XV Congresso Ibero-LatinoAmerincano do Asfalto. Braga - Portugal : Barbosa \& Xavier, Lda., 2009. v. 1. p. 395-404.

Mendes, L. O (2011) A utilização do método Bailey para a seleção de agregados em misturas asfálticas. Dissertação (Mestrado). Programa de Pós-Graduação em Ambiente Construído, Universidade Federal de Juiz de Fora. Juiz de Fora.

Morilha Jr., A (2004) Estudos Sobre a Ação de Modificadores no Envelhecimento dos Ligantes Asfálticos e nas Propriedades Mecânicas e de Fadiga das Misturas Asfálticas. Dissertação (Mestrado). Programa de Pós-Graduação em Engenharia Civil, Universidade Federal de Santa Catarina. Florianópolis.

Nascimento, L. A. H (2008) Nova Abordagem da Dosagem de Misturas Asfálticas Densas com Uso do Compactador Giratório e Foco na Deformação Permanente. 204p. Dissertação (Mestrado). COPPE/ Programa de Engenharia Civil, Universidade Federal do Rio de Janeiro Rio de Janeiro.

NOVADUTRA (2011) Estudo comparativo do comportamento de fadiga de misturas betuminosas com diferentes teores de asfalto. Disponível em: <http://www.antt.gov.br/html/objects/_downloadblob .php?cod_blob=3250>. (Acesso em: 18/11/2011).

Vale, A. C (2007) Estudo Laboratorial da Viabilidade do Uso de Fibras de Coco em Misturas Asfálticas do Tipo SMA. Dissertação (Mestrado), Programa de Mestrado em Engenharia de Transportes, Universidade Federal do Ceará. Fortaleza.

Vavrik, W. R., G. Huber, W. Pine et al (2002) Bailey Method for Gradation Selection in HMA Mixture Design. Transportation Research Board: Transportation Research Circular Number E-C044, Washington, D. C., EUA.

Vavrik, W. R., W. J. Pine, G. Huber et al (2001)The Bailey Method of Gradation Evaluation: The Influence of Aggregate Gradation and Packing Characteristics on Voids in the Mineral Aggregate. Journal of the Association of Asphalt Paving Technologists, v. 70, p. $132-175$. 